\title{
Migration: Issues of Health and Well Being
}

\section{A. A. Mamun Hussain ${ }^{1}$}

The fresh influx of the Rohingyas ${ }^{1,2}$ to Bangladesh is not a standalone incident. As of 18 march, 2018, a report, ${ }^{3}$ supported by U N H C R has counted 836,210 Rohingya refugees in total in camps and settlement, including arrival both before and after August, 2017. History reveals that mobility is a fundamental human activity, a vital component of developing human capital and a powerful driver of social change. More people than ever before now live in a different country to the one in which they were born, either by choice or because they were forced to do so. According to a UN estimation, one-third of the world's population can be defined as migrants, when four out of every five migrants come from a developing country, and many developing countries are also important transit and destination location.

The factors which influence migration can be described as 'Pull' or 'Push' factors. Pull factors attract the individual for economic betterment or for educational uplift, whereas push factors include political factors which may extrude individual out of one culture into another. The process of migration can be divided into three stages:

\begin{tabular}{|l|l|l|}
\hline a. & Premigration: & $\begin{array}{l}\text { Decision and preparation for such } \\
\text { move. }\end{array}$ \\
\hline b. & Migration: & $\begin{array}{l}\text { The physical relocation from one } \\
\text { site to another. }\end{array}$ \\
\hline & $\begin{array}{l}\text { Adjustment to social, political, } \\
\text { economic and cultural } \\
\text { framework of the new society. }\end{array}$ \\
\hline
\end{tabular}

Researchers ${ }^{4,5}$ consider the impact of migration on various level on the individual who migrate, on the families and individuals they leave behind or bring with them, on the culture and community they move to and the cultures and communities they leave behind. Although, talking on impact of migration, many a authority talk only about cultural bereavement, stress and development of different mental disorders, it is well established that migrants make huge contributions to the local culture and economy as well as to the economies of the countries or regions they originate from, thus contributing heavily to these regions and to the local GDP in a positive manner.

There is considerable evidence in the literature ${ }^{6,7,8}$ to suggest that some migrants groups are more prone to certain group of mental illness than others. To summarize, migrants have a strongly increased risk for schizophrenia, depression PTSD, addictive disorder, suicide and suicidal behavior. To note, the vulnerable groups, viz, the elderly, the woman, the children and the ethnic minorities are at more precarious state. Furthermore, with an increasing awareness of mental health in the migrant population, underpinning of the relation it shares with the physical illness cannot be underscored. Clinicians must recognize that physical illness will affect the mental health of migrants and vice versa, and therefore they must be cognizant of physical factors.

In this regard, although the infections, pregnancyrelated complications, STI, drug resistant TB, HIV and other non-communicable disease are more rampant, but medically unexplained symptoms may add further to the burden of care.

As the interaction between physical and mental health is a complex one, a key to understanding help-seeking is the way in which individuals and their families and culture see mind-body dualism,

1 Professor, Department of Psychiatry, Rajshahi Medical College 
so that it help to appreciate that physical ill-health will affect mental health, and emotional distress in turn influences physical health. Therefore, the clinician today must be aware of subtle cultural nuances, cultural norms and explanations, so that patients and their families can engage in the therapeutic process effectively.

Considering different evidence and guidelines ${ }^{9,10,11}$ following recommendations are often suggested:

\section{For policy makers:}

Should have policies regarding housing, employment and physical and mental health needs of the migrants.

Appropriate resources to meet the needs.

Appropriate resources for training of professional.

Communication strategies should address concept of public mental health and public education about migration.

Collection of accurate data and information.

\section{For service providers:}

Services should be culturally, geographically and emotionally accessible.

Separate or mainstream services should be according to local need.

Provision for cultural competence and diversity training.

Determination of local needs.

Regular audit of services.

To consider culture mediator and culture broker for interpretation.

\section{For clinician:}

Availability of clear information and resources.

Cultural awareness and cultural competency training.

Specialist or generalist services should be according to need and resources.

Cultural training for ALL health professionals.

As a concluding remark it can be added that, migration has been going on for millennia. But, because of the heterogeneous experiences of migration and setting down in the new countries they also have special needs such

as lack of linguistic abilities which must be taken into account using a number of strategies at individuals, local and national policy levels. Finally, as the issues of migration is included in the 2030 agenda for sustainable development, it demands suitable strategy and its necessary implications from the policy makers of the every

country.

\section{References:}

1. Noor T, Islam SM \& Forid S. Rohingya crisis and the concern for Bangladesh. Int. Jr. of Scientific \& Engineering Research Vol. 8. Iss. 12, Dec, 2011.

2. Aparupa B. Rohingya crisis: Policy option and analysis. BIPSS Special report 2017

3. Rohingya Refugee crisis, Cox's Bajar ISCG (Inter Sector Co-ordination Group) situation report, 25 march, 2018.

4. Maharaj AS, Nayar S \& Choummanivong MC. Developing culturally responsive services for working with refugee youth with mental health concerns. National Centre of Mental Health Research, 2008. www.tepou.com.nz.

5. Bhugra D, Craig T, Bhui K. Mental Health of refugees and asylum seekers. OUP, 2010.

6. James B. Kirkbride \& Peter B J. Epidemiological aspects of migration and mental illness. In migration \& mental health. Ed. Bhugra D. Gupta S. Cambridge University Press, 2011. P.15-36.

7. Kalra G. Natarajesh P. \& Bhugra D. Migration \& physical illness. In migration and Mental Health. Ed. Bhugra D. Gupta S. Cambridge university press, 2011. P-299-308.

8. Kemp C, Rasbridge L. Refugee and immigrant Health. Cambridge university Press, 2004.

9. Bhugra D. Gupta S. \& Schouler-Ocak et al. EPA Guidance Mental Health care of migrants. European Psychiatry, 29 (2014) 107-115.

10. WHO, World Health Report 2001. Mental health: new understanding new hope. WHO. 2001.

11. Zimmerman CKL, Hossain M. Migration and health: a framework for $21^{\text {st }}$ century policy-making PLoS Med. 2011; 815. 